\title{
Elasticity moduli of expansive soils from dimensional analysis
}

Hana H. Adem MSC

Research Associate, Department of Civil Engineering, University of Ottawa, Ottawa, Ontario, Canada
Sai K. Vanapalli PhD, PEng

Professor and Chair, Department of Civil Engineering, University of Ottawa, Ottawa, Ontario, Canada

In this paper, a dimensionless model is proposed to estimate the modulus of elasticity of unsaturated expansive soils extending the dimensional analysis (DA). Experimental results of conventional and suction-controlled triaxial tests for three different compacted expansive soils from the literature are used in this study to apply the DA. The state of hydration of soil expressed in terms of the matrix suction and the degree of saturation, the level of compaction and the confinement described by the initial void ratio and the confining stress, respectively, are considered to form the dimensionless parameters towards reliably estimating the soil modulus of elasticity. Validation of the proposed dimensionless model is achieved by comparing its estimations of the soil modulus of elasticity with the experimental values of the modulus of elasticity obtained from the results of triaxial shear tests. In addition, the estimated values of the modulus of elasticity from another semi-empirical model presented by the present authors, for the three unsaturated expansive soils used in this study, are used to verify the proposed dimensionless model. The dimensionless model is rigorous and reliable for estimating the modulus of elasticity of unsaturated expansive soils.

\section{Notation}

$D \quad$ independent primary dimension

E initial tangent modulus of elasticity

$E_{\text {sat }} \quad$ elasticity modulus of soil under saturated condition

$E_{\text {unsat }} \quad$ elasticity modulus of soil under unsaturated condition

$e_{0}$

$f$

$G_{\mathrm{s}}$

$h_{0}$

$I_{\mathrm{p}}$

$K$ and $n$

L

$l$

M

m

N

$P_{\text {a }}$

$\left(u_{\mathrm{a}}-u_{\mathrm{w}}\right)$

$R^{2}$

$S$

$T$

V

$V_{\mathrm{s}}$

$V_{\text {vo }}$

$V_{\mathrm{w}}$

$W_{\mathrm{L}}$

$W_{\mathrm{p}}$

X

$\alpha, \beta$

$\Delta h$
$\Delta\left(\sigma_{1}-\sigma_{3}\right)$ change in the deviator stress

$\varepsilon \quad$ axial strain

$\gamma_{\mathrm{d}} \quad$ dry unit weight

$\pi \quad$ dimensionless parameter (i.e. Pi group)

$\sigma_{3} \quad$ confining stress

$\left(\sigma_{1}-\sigma_{3}\right) \quad$ deviator stress

$\left(\sigma_{1}-\sigma_{3}\right)_{\mathrm{f}} \quad$ failure deviator stress

$\left(\sigma_{1}-\sigma_{3}\right)_{\mathrm{u}} \quad$ ultimate deviator stress at large strain

\section{Introduction}

The soil modulus of elasticity is a fundamental parameter in understanding and estimating the volume change behaviour of expansive soils associated with variations of environmental conditions (Adem and Vanapalli, 2013; Vanapalli and Adem, 2013). It is therefore one of the most important soil properties in geotechnical engineering design of both substructures and superstructures constructed in or on expansive soils. To conduct a reliable geotechnical design and analysis, it is often desirable to effectively describe the soil modulus of elasticity as a function of its influencing parameters.

The modulus of elasticity of unsaturated soils depends on numerous parameters, such as $(i)$ the initial level of compaction (dry unit weight or void ratio), (ii) the initial state hydration (water content, degree of saturation or matric suction) and (iii) the confinement (deviator stress or lateral stress). The other factors that affect the modulus of elasticity include variables such as boundary conditions, Poisson's ratio, sample dimensions, soil structure (the size of soil particles), stress path and stress history, to list a few. The influence of all these parameters should be considered for a reliable estimation of the soil modulus of elasticity. However, 
accounting the influence of all these parameters requires extensive experimental programs and multi-variable regression analyses. Such an approach is cumbersome to implement in conventional geotechnical engineering practice. Due to this reason, the modulus of elasticity of unsaturated soils has been expressed in the literature as a function of only one or two parameters. For example, Zhang et al. (2012) and Lu and Kaya (2014) proposed a power function to quantitatively describe the relationship between the soil modulus of elasticity and the soil water content. Adem and Vanapalli (2014) used a semi-empirical model for estimating the modulus of elasticity of unsaturated expansive soils as a function of the matrix suction changes, neglecting the influence of mechanical stress changes. Some investigators (Rahardjo et al., 2011) have linked the modulus of elasticity to a change in both the net normal stress (i.e. the mechanical stress) and the matrix suction using multiple regression methods; such an approach is rigorous but is time consuming from the view point of conducting various experimental studies.

To alleviate some of the challenges associated with conducting cumbersome experimental investigations to estimate the modulus of elasticity of unsaturated expansive soils, dimensional analysis (DA) is used in this paper as a tool to propose an alternative approach. Some researchers (Butterfield, 1999; Buzzi, 2010; Buzzi et al., 2011; Palmer, 2008) have used the DA in a few geotechnical engineering applications; however, this approach is not widely used in practice. One of the main advantages of the DA is that it allows intelligent experiments, i.e. a reduction of the number of tests to be performed to characterise a physical phenomenon taking account of the influence of all the parameters of an activity or a phenomenon in the engineering applications. This is possible through the use of dimensionless parameters, the number and form of which can be derived from the Buckingham Pi theorem (Buckingham, 1914).

For soils under unsaturated conditions, Matyas and Radhakrishna (1968), Barden et al. (1969), Fredlund and Morgenstern (1977), Alonso et al. (1990) and Gallipoli et al. (2003) proposed a constitutive equation in terms of the soil void ratio with respect to the changes associated with the net normal stress (i.e. the mechanical stress) and the matrix suction. Along similar lines, a dimensionless model extending the DA is proposed in this study to estimate the modulus of elasticity for unsaturated expansive soils, considering the influence of the state of hydration of soil expressed in terms of the matrix suction and the degree of saturation, the level of compaction and the confinement described by the initial void ratio and the confining stress respectively. Experimental results of conventional and suction-controlled triaxial tests for three different expansive soils from Zao-Yang, Nanyang and Guangxi in China published in Zhan (2003), Miao et al. (2002) and Miao et al. (2007) respectively are analysed to form the dimensionless parameters towards reliably estimating the soil modulus of elasticity. Validation of the proposed dimensionless model is conducted by comparing its estimations of the elasticity moduli with the experimental values of the elasticity moduli obtained from the triaxial shear tests. In addition, the estimated values of the elasticity moduli from another semi-empirical model presented by Adem and Vanapalli (2014), for the three unsaturated expansive soils used in this study, are used to verify the proposed dimensionless model.

\section{Dimensional analysis background}

The DA is a mathematical tool that shapes the general form of relations that describe natural phenomena. The application of DA to any particular physical phenomenon is based on the premise that the phenomenon can be described by a list $(V)$ of $l$ variables $\left(V_{1}, V_{2}, \ldots\right.$, $V_{l}$ ), encompassing a total of $m$ independent primary dimensions $(D)=\left(D_{1}, D_{2}, \ldots, D_{m}\right)$ (e.g. mass, length, time, temperature), which is the minimum number of reference dimensions required to describe the physical variables. The term 'variables' includes both independent parameters of a specific system (e.g. size, density, mass) and dependent quantities such as displacements, stresses and bending moments (Butterfield, 1999).

The objective of the DA is to minimise the dimension space in which the behaviour of a specific system might be studied by combining assumed governing variables $V$ into $N$ dimensionless parameters, with $N$ being less than $V$. In particular, Buckingham's theorem (Buckingham, 1914) states that an initial equation involving $l$ variables and $m$ dimensions can always be reduced to a dimensionless relationship involving only $N$ dimensionless parameters, where

1. $N=l-m$

The resulting $N$ dimensionless parameters are conventionally labelled as $\left(\pi_{1}, \pi_{2}, \ldots, \pi_{N}\right)$ (i.e. Pi groups). As each $\pi$ is dimensionless, the final function must be dimensionless and therefore dimensionally

2. $f\left(\pi_{1}, \pi_{2}, \ldots, \pi_{N}\right)=M^{0} L^{0} T^{0}$

The form of function $f$ is not provided by the DA, but it is usually approximated by an empirical, dimensionless equation fitted to either model or prototype data. In addition, the Buckingham theorem does not provide any specific guidance related to the choice of variables, which appear in each $N$ parameter (i.e. Pi group) used for the reduction of the problem. In order to enable systematic computation of dimensionless numbers, the input and output variables of a concept are considered as performance variables. The choice of repeating variables should be done within the concept's internal variables and according to the unique number of the system's governing dimensions for best results (Christophe et al., 2008).

\section{Dimensional analysis and combination of parameters}

The DA has been used as a tool in this study to propose a dimensionless model for estimating the modulus of elasticity of unsaturated expansive soils. The application of DA to account for all of the factors influencing the value of the modulus of elasticity of 
unsaturated expansive soils is challenging. This is due to numerous properties and parameters that influence the modulus of elasticity of unsaturated soils. In the present study, initial void ratio, matrix suction, degree of saturation, confining pressure and deviator stress changes are assumed to be primary factors. Experimental data resulting from triaxial shear tests on unsaturated expansive soils, performed under different confining stresses with varying matrix suctions, are used to apply the DA. Hence, the primary factors influencing the soil modulus of elasticity can be expressed in terms of the initial height of soil specimen $h_{0}$, the change in specimen height upon compression $\Delta h$, the volume of voids $V_{\text {vo }}$, the volume of water $V_{\mathrm{w}}$, the volume of solid particles $V_{\mathrm{s}}$, the matrix suction $\left(u_{\mathrm{a}}-\right.$ $\left.u_{\mathrm{w}}\right)$, the confining stress $\sigma_{3}$ and the change in deviator stress $\Delta\left(\sigma_{1}-\right.$ $\left.\sigma_{3}\right)$. The modulus of elasticity of unsaturated expansive soils can be described using the list of these parameters, as shown in Equation 3

3. $f\left[\Delta h, h_{0}, V_{\mathrm{vo}}, V_{\mathrm{s}}, V_{\mathrm{w}},\left(u_{\mathrm{a}}-u_{\mathrm{w}}\right), \Delta\left(\sigma_{1}-\sigma_{3}\right), \sigma_{3}\right]=0$

Equation 3 involves eight independent variables and three dimensions (mass, length and time). According to the Buckingham Pi theorem (Buckingham, 1914), Equation 3 can be reduced to a simpler equation involving five dimensionless parameters (i.e. eight independent variables - three dimensions), which depend on the combination of variables present in Equation 3. For a group of variables appearing in each dimensionless parameter, they have to be combined in such a way that the powers of each of the 'dimensions' appearing in the group are separately zero. Several combinations are possible to form dimensionless parameters. However, the correct sets of dimensionless parameters are needed to be selected and have to be verified through experimental evidence. Equation 4 presents the used dimensionless parameters that are chosen in this study based on obtaining the most satisfactory agreement between the experimental and estimated values of the soil modulus of elasticity.

4.

$$
f\left(\frac{E_{\text {unsat }}-E_{\text {sat }}}{P_{\mathrm{a}}}, \frac{\left(\sigma_{3}-u_{\mathrm{a}}\right)\left(u_{\mathrm{a}}-u_{\mathrm{w}}\right)}{P_{\mathrm{a}}^{2}}, \frac{\left(u_{\mathrm{a}}-u_{\mathrm{w}}\right)}{P_{\mathrm{a}}}, S, e_{0}\right)=0
$$

where $E_{\text {unsat }}$ and $E_{\text {sat }}$ are the elasticity moduli under unsaturated and saturated conditions respectively, $S$ is the degree of saturation, $e_{0}$ is the initial void ratio and $P_{\mathrm{a}}$ is the atmospheric pressure (i.e. $101 \cdot 3 \mathrm{kPa}$ ) used for maintaining the parameters of Equation 4 dimensionless. The DA is applied on experimental results of conventional and controlled-suction triaxial tests available in the literature. The state of hydration of the soil is expressed in terms of the matrix suction and the degree of saturation, the level of compaction is described by the initial void ratio, and the confinement is described by the confining stress. For simplicity and to significantly reduce the number of tests required, the four dimensionless parameters that are related to the degree of saturation, matrix suction, initial void ratio and net confining stress for each of the tests are incorporated into one unique dimensionless parameter $X$. This is more convenient as the equation to estimate the modulus of elasticity of unsaturated soils can be reduced to a relationship between only two entities. Using $X$ allows accounting for the four influencing parameters via only one dimensionless parameter, and Equation 4 is modified to

5. $f\left(\frac{E_{\text {unsat }}-E_{\text {sat }}}{P_{\mathrm{a}}}, X\right)=0$

The parameter $X$ can be defined in terms of several combinations of the dimensionless parameters by a calibration procedure. The calibration in this study is achieved using a program code for the suggested formula of $X$ that incorporates the dimensionless parameters with several exponents. The program code changes the exponents for the formula incrementally and calculates the soil modulus of elasticity. The calibrated formula of $X$ is determined on the basis of the best agreement between the experimental and estimated values of the soil modulus of elasticity. Based on the results of triaxial tests for the three unsaturated expansive soils from Zao-Yang, Nanyang and Guangxi in China, which are used in this study, the following relationship is suggested to be the calibrated formula of $X$

6.

$$
X=\left(\frac{1}{e_{0}}\right)\left\{\left[\frac{\left(\sigma_{3}-u_{\mathrm{a}}\right)\left(u_{\mathrm{a}}-u_{\mathrm{w}}\right)}{P_{\mathrm{a}}^{2}}\right]+\left[S^{0.1} \frac{\left(u_{\mathrm{a}}-u_{\mathrm{w}}\right)}{P_{\mathrm{a}}}\right]\right\}^{0.7}
$$

The relation of the exponents of Equation 6 with other factors influencing the soil modulus of elasticity under unsaturated condition is not clear. The exponents of the equation could depend on soil structure, mechanical history and other soil properties. No unique or well-defined relationship could be derived despite attempts to correlate the values of the exponents to the soil properties reported from the three investigated studies (Miao et al., 2002, 2007; Zhan, 2003).

According to the DA, Equation 5 can be written in terms of the dimensionless parameter $X$ as

$$
\text { 7. } \frac{E_{\text {unsat }}-E_{\text {sat }}}{P_{\text {a }}}=f(X)
$$

The only manner to assess this relationship (Equation 7) (i.e. the proposed dimensionless model) is to use experimental data and plot the results in terms of $X$ versus $\left(E_{\text {unsat }}-E_{\text {sat }}\right) / P_{\mathrm{a}}$. Results of triaxial tests for unsaturated expansive soils available in the literature are used for examining the validity of Equation 7. The values of elasticity moduli of soils in the first entity of Equation 7 are experimentally determined from the stress-strain curves of triaxial tests during shearing of saturated/unsaturated compacted specimens under different values of confining stresses and matrix suctions. If a good correlation with a reasonable coefficient of determination $R^{2}$ could be found between the two entities $X$ and $\left(E_{\text {unsat }}-E_{\text {sat }}\right) / P_{\text {a }}$, 
Equation 7 would be used to back-calculate the soil modulus of elasticity at any unsaturated condition.

Typically, stress-strain data from triaxial shear tests can be represented mathematically by a hyperbola (Figure 1) having the form below (Duncan and Chang, 1970)

8.

$$
\left(\sigma_{1}-\sigma_{3}\right)=\frac{\varepsilon}{\frac{1}{E}+\frac{\varepsilon}{\left(\sigma_{1}-\sigma_{3}\right)_{\mathrm{u}}}}
$$

where $\varepsilon$ is the axial strain, $E$ is the initial tangent modulus of elasticity and $\left(\sigma_{1}-\sigma_{3}\right)_{\mathrm{u}}$ is the ultimate deviator stress. The hyperbola is considered valid up to the actual soil failure (i.e. the actual failure deviator stress $\left.\left(\sigma_{1}-\sigma_{3}\right)_{\mathrm{f}}\right)$ (point $\mathrm{A}$ in Figure 1). The value of the parameters of the hyperbolic model (Equation 8) $E$ and $\left(\sigma_{1}-\sigma_{3}\right)_{\mathrm{u}}$ can be determined by plotting the stress versus strain relationships on transformed axes axial strain $\varepsilon$ and axial strain/deviator stress $\varepsilon$ / $\left(\sigma_{1}-\sigma_{3}\right)$, as shown in Figure 2, and represented by a straight line having the form

$$
\text { 9. } \frac{\varepsilon}{\left(\sigma_{1}-\sigma_{3}\right)}=\frac{1}{E}+\frac{\varepsilon}{\left(\sigma_{1}-\sigma_{3}\right)_{\mathrm{u}}}
$$

The intercept and the slope of the resulting straight line are the inverse of the initial tangent modulus of elasticity $1 / E$ and the inverse of ultimate deviator stress $1 /\left(\sigma_{1}-\sigma_{3}\right)_{\mathrm{u}}$ respectively (Duncan and Chang, 1970). The experimental values of the modulus of elasticity are determined in this study as the reciprocal of the intercept of the resulting straight line.

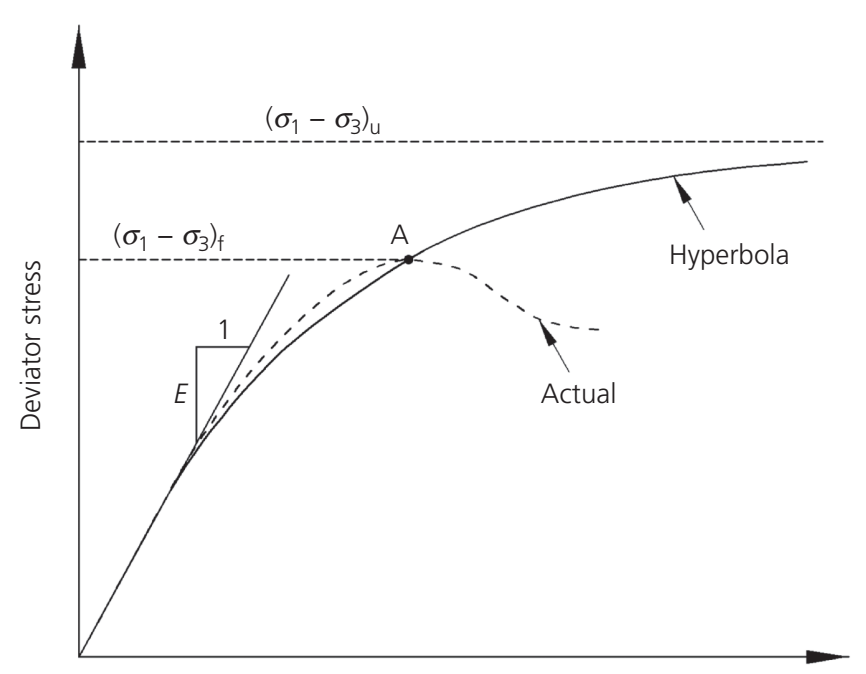

Axial strain

Figure 1. Comparison of typical stress-strain curve with hyperbolic stress-strain curve (modified after Duncan and Chang (1970))

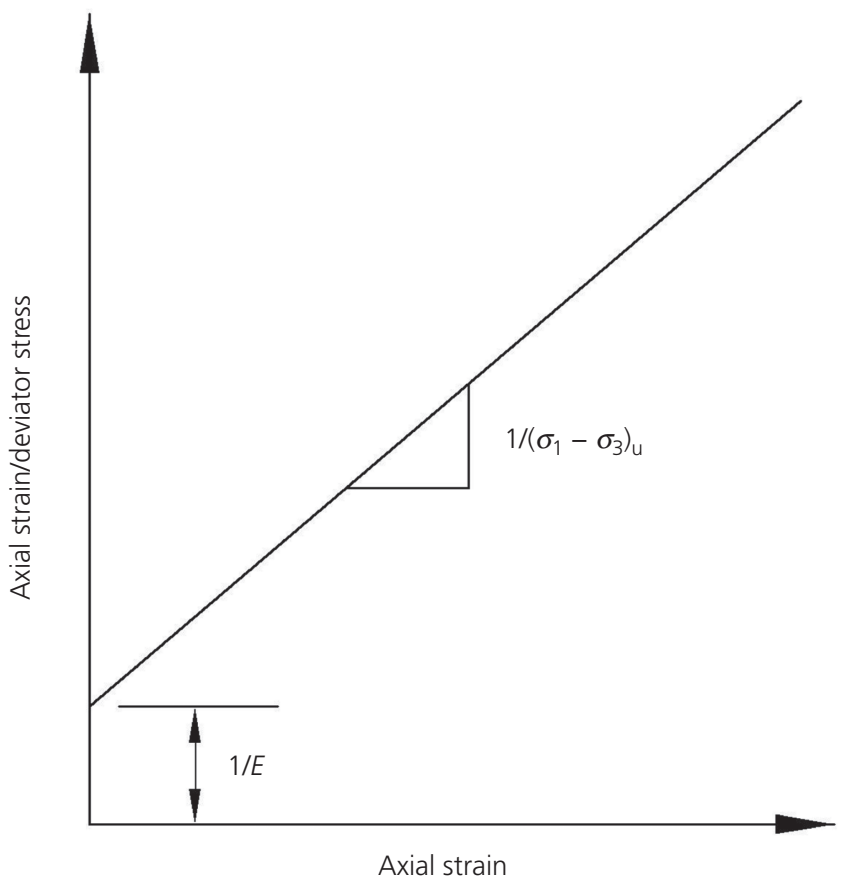

Figure 2. Transformed hyperbolic stress-strain curve (modified after Duncan and Chang (1970))

The above analysis has been extended, and comparisons are provided between the values of the modulus of elasticity derived from triaxial test results and Equation 7 (i.e. the dimensionless model) to check its capability to estimate the soil modulus of elasticity.

\section{Triaxial test results used in the DA}

Three data sets from Zhan (2003), Miao et al. (2002) and Miao et al. (2007) for the compacted expansive soils from Zao-Yang, Nanyang and Guangxi in China respectively are used in the DA. These three soils are hereafter labelled as soil A (from Zao-Yang), soil B (from Nanyang) and soil C (from Guangxi) for simplicity. Figure 3 shows the soil-water characteristic curves for the three investigated expansive soils (soils A, B and C) measured using the pressure plate extractor technique. Table 1 summarises key properties of these soils. The results of conventional and suctioncontrolled triaxial tests on saturated and unsaturated compacted specimens of these three soils under different confining stresses and matrix suctions can be found in Zhan (2003), Miao et al. (2002) and Miao et al. (2007).

\section{Analysis of the triaxial test results}

The stress versus strain relationships of the triaxial tests for the three expansive soils used in this study (i.e. soils A, B and C) were analysed and plotted on the transformed axes $\varepsilon$ and $\varepsilon /\left(\sigma_{1}-\sigma_{3}\right)$ as suggested by Duncan and Chang (1970). The straight line equation (Equation 9) was used to fit the data. The experimental values of the 
Elasticity moduli of expansive soils from

dimensional analysis

Adem and Vanapalli

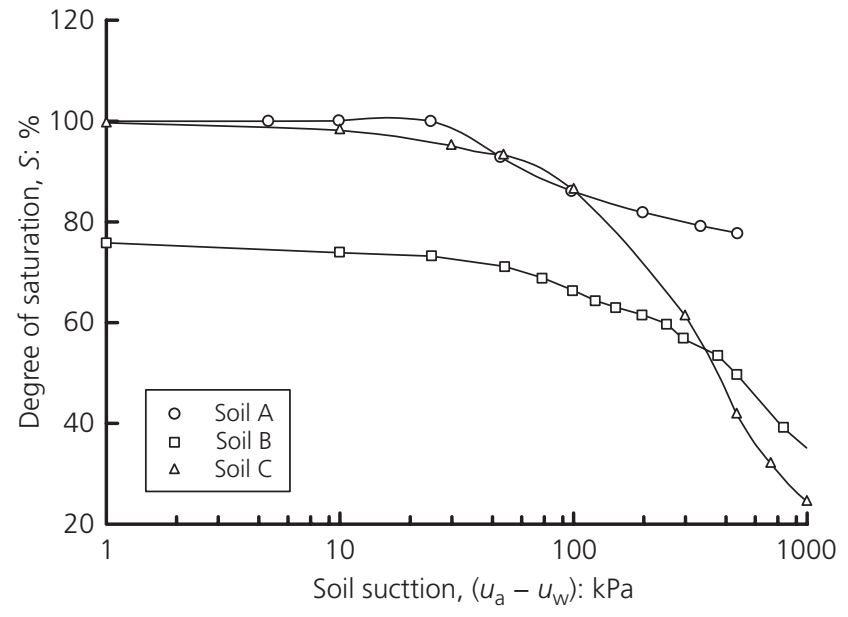

Figure 3. Soil-water characteristic curves for the three expansive soils used in this study

soil modulus of elasticity were determined as the reciprocal of the intercepts of the straight lines.

Figures 4 and 5 show the transformed stress-strain curves for the saturated and unsaturated specimens of soil A respectively. The experimental values of elasticity moduli for soil A under saturated and unsaturated conditions are shown in Figures 4 and 5 and summarised in Table 2. Review of Figure 4 and Table 2 shows that the experimental value of the saturated modulus of elasticity increases with an increase in the applied confining stress. This is consistent with the relationship proposed by Janbu (1963), in which the soil modulus of elasticity under saturated condition was nonlinearly related to the confining stress (Equation 10).

10.

$$
E=K P_{\mathrm{a}}\left(\frac{\sigma_{3}}{P_{\mathrm{a}}}\right)^{n}
$$

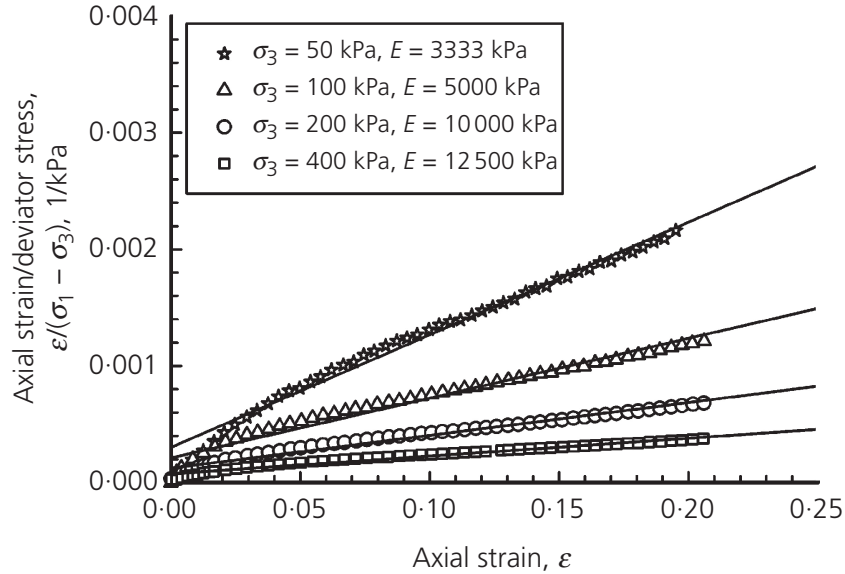

Figure 4. Transformed stress-strain curve for the saturated compacted specimens of soil A

where $K$ and $n$ are the fitting parameters, and $P_{\mathrm{a}}$ is the atmospheric pressure expressed in the same stress units as $E$ and $\sigma_{3}$. Janbu's relationship (Janbu, 1963) given in Equation 10 was used to fit the data of the saturated compacted specimens of soil A (Figure 6). The coefficient of determination of the best-fit equation is relatively high $\left(R^{2}=0.97\right)$. As a result, the modulus of elasticity of soil $\mathrm{A}$ at any confining stress can be estimated using Equation 11

11. $\frac{E}{P_{\mathrm{a}}}=53.29\left(\frac{\sigma_{3}}{P_{\mathrm{a}}}\right)^{0.67}$

Review of Figure 5 and Table 2 shows that the modulus of elasticity of soil A under unsaturated condition increases with an increase in the matrix suction $\left(u_{\mathrm{a}}-u_{\mathrm{w}}\right)$. This is consistent with the observations of other investigators in the literature (Costa et al., 2003; Fredlund and Rahardjo, 1993; Inci et al., 2003; Lu and Likos, 2006; Oh

\begin{tabular}{|c|c|c|c|c|c|c|}
\hline \multirow[t]{2}{*}{ Soil type } & $\begin{array}{c}\text { Plasticity } \\
\text { index }\end{array}$ & $\begin{array}{l}\text { Liquid } \\
\text { limit }\end{array}$ & $\begin{array}{c}\text { Plastic } \\
\text { limit }\end{array}$ & $\begin{array}{c}\text { Specific } \\
\text { gravity }\end{array}$ & $\begin{array}{l}\text { Dry unit } \\
\text { weight }\end{array}$ & $\begin{array}{c}\text { Free } \\
\text { swelling }\end{array}$ \\
\hline & $l_{p}: \%$ & $W_{L}: \%$ & $W_{p}: \%$ & $G_{s}$ & $\begin{array}{c}\gamma_{\mathrm{d}}: \mathrm{kN} / \\
\mathrm{m}^{3}\end{array}$ & $\%$ \\
\hline $\begin{array}{l}\text { Soil A } \\
\text { Zhan (2003) }\end{array}$ & $31 \cdot 0$ & $50 \cdot 5$ & $19 \cdot 5$ & $2 \cdot 67$ & $15 \cdot 30$ & - \\
\hline $\begin{array}{l}\text { Soil B } \\
\text { Miao et al. (2002) }\end{array}$ & $31 \cdot 8$ & $58 \cdot 3$ & $26 \cdot 5$ & $2 \cdot 7$ & $14 \cdot 72$ & 74 \\
\hline Soil C & $31 \cdot 1$ & $61 \cdot 4$ & $30 \cdot 3$ & $2 \cdot 7$ & $14 \cdot 52$ & 45 \\
\hline
\end{tabular}

Table 1. Soil properties of the three expansive soils used in this study 
Geotechnical Research

Volume 1 Issue 2
Elasticity moduli of expansive soils from

dimensional analysis

Adem and Vanapalli
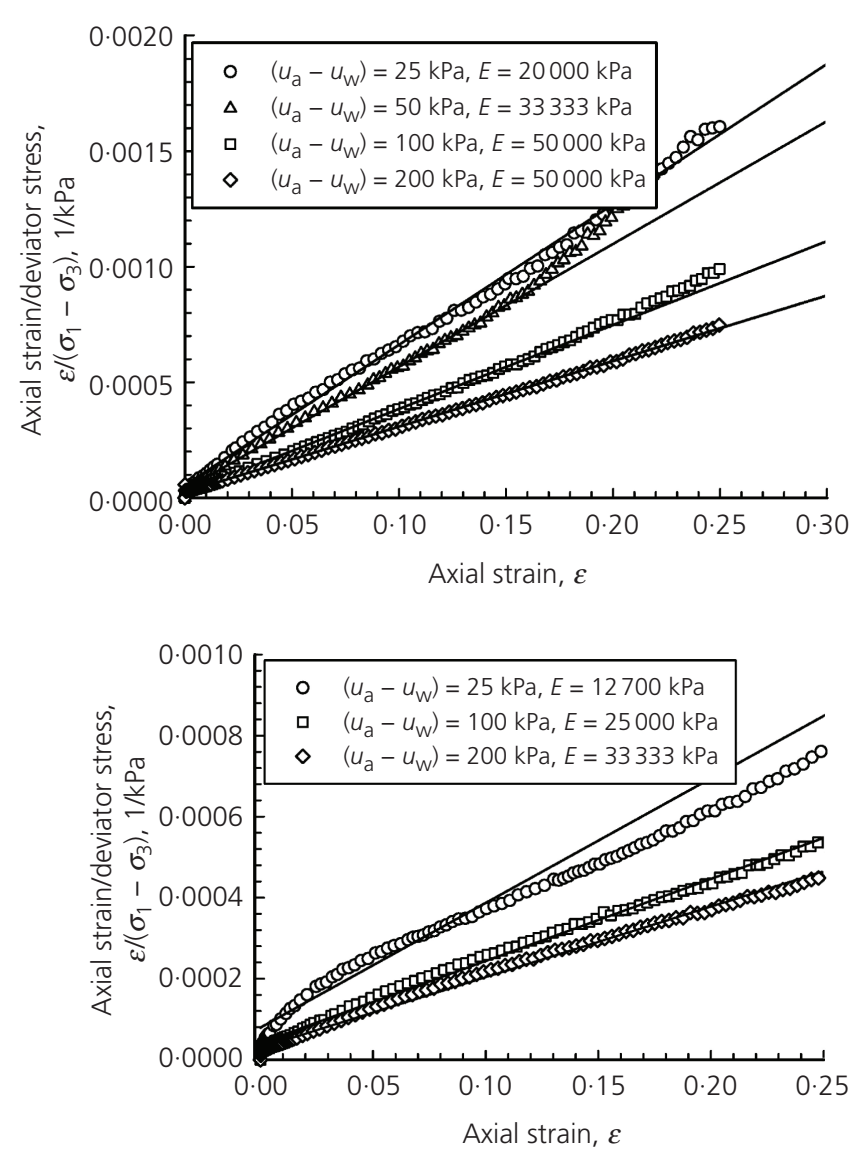

Figure 5. Transformed stress-strain curves for the unsaturated compacted specimens of soil $\mathrm{A}$ : at net confining stress of (a) $50 \mathrm{kPa}$ and (b) $200 \mathrm{kPa}$

et al., 2009; Vanapalli and Oh, 2010; Yang et al., 2005, 2008). However, some data sets (e.g. data set for $\left(\sigma_{3}-u_{\mathrm{a}}\right)=200 \mathrm{kPa}$ and $\left(u_{\mathrm{a}}-u_{\mathrm{w}}\right)=25 \mathrm{kPa}$ (Figure 5(b)) are not linear; such a behaviour can be attributed to the stress-strain curve not following the hyperbolic trend with respect to its shape. Nonetheless, a straight line could

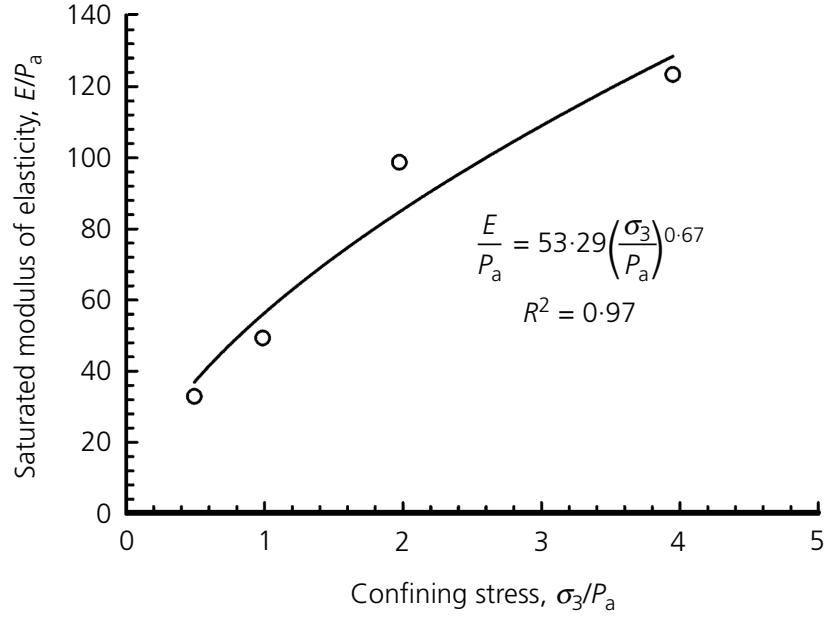

Figure 6. Relationship of the saturated modulus of elasticity with the confining stress for the compacted specimens of soil $A$

still be fitted to the data. This assumption is reasonably valid as the coefficient of determination was relatively high $\left(R^{2}>0 \cdot 96\right)$.

A similar analysis was conducted for soils B and C to determine their experimental values of elasticity moduli. These values are summarised in Tables 3 and 4.

Table 3 shows the experimental values of elasticity moduli obtained from 12 triaxial tests carried out by Miao et al. (2002) on soil B under unsaturated conditions using different net confining stresses and matrix suctions. However, to estimate the modulus of elasticity of soil B under unsaturated conditions using the DA approach, at least three of the soil specimens have to be tested under the same confining stress with varying initial matrix suctions. Due to this reason, the tests conducted by Miao et al. (2002) on the soil specimens under unsaturated conditions were divided into three groups. Every group consists of four tests having a close net confining stress. The net confining stress for each group was determined as an average value of the net confining stresses of
Net confining

stress $\left(\sigma_{3}-u_{\mathrm{a}}\right): \mathrm{kPa}$
Saturated modulus

of elasticity $E_{\text {sat: }}: \mathrm{kPa}$
Matrix suction $\left(u_{a}-u_{w}\right): k P a$

$25 \quad 100 \quad 200$

Unsaturated modulus of elasticity $E_{\text {unsat: }} \mathrm{kPa}$

\begin{tabular}{lrcccc}
\hline 50 & 3333 & 20000 & 33333 & 50000 & 50000 \\
100 & 5000 & - & - & - & - \\
200 & 10000 & 12700 & - & 25000 & 33333 \\
400 & 12500 & - & - & -
\end{tabular}

Table 2. Experimental values of elasticity moduli obtained from triaxial tests for the compacted specimens of soil A under saturated and unsaturated conditions (data from Zhan, 2003) 


\begin{tabular}{|c|c|c|c|c|c|c|}
\hline \multirow{3}{*}{$\begin{array}{l}\text { Net confining } \\
\text { stress }\left(\sigma_{3}-u_{\mathrm{a}}\right): \mathrm{kPa}\end{array}$} & \multirow{3}{*}{$\begin{array}{l}\text { Average confining } \\
\text { stress: } \mathrm{kPa}\end{array}$} & \multirow{3}{*}{$\begin{array}{l}\text { Saturated modulus } \\
\text { of elasticity } E_{\text {sat: }} \mathrm{kPa}\end{array}$} & \multicolumn{4}{|c|}{ Matrix suction $\left(u_{a}-u_{w}\right): \mathrm{kPa}$} \\
\hline & & & 50 & 80 & 120 & 200 \\
\hline & & & \multicolumn{4}{|c|}{ Unsaturated modulus of elasticity $E_{\text {unsat: }} \mathrm{kPa}$} \\
\hline 20 & 25 & $9253^{a}$ & - & 25000 & - & 50000 \\
\hline 30 & & $12921^{a}$ & 25000 & - & 33333 & - \\
\hline 50 & $62 \cdot 5$ & 20000 & 33333 & - & - & 50000 \\
\hline 70 & & $25964^{a}$ & - & 33333 & - & - \\
\hline 80 & & $28982^{a}$ & - & - & 50000 & - \\
\hline 100 & $112 \cdot 5$ & 33333 & 50000 & - & - & 50000 \\
\hline 120 & & $40473^{a}$ & - & 50000 & - & - \\
\hline 130 & & $43231^{a}$ & - & - & 50000 & - \\
\hline 150 & - & 50000 & - & - & - & - \\
\hline
\end{tabular}

aThe value obtained from the best fit of the relationship between the saturated modulus of elasticity and the confining stress using Janbu's relationship (Janbu, 1963) given in Equation 10; the fitting parameters $K=347 \cdot 47, n=0 \cdot 82$.

Table 3. Experimental values of elasticity moduli obtained from triaxial tests for the compacted specimens of soil B under saturated and unsaturated conditions (data from Miao et al., 2002)

$\begin{array}{lr}\text { Net confining stress } & \text { Saturated modulus of } \\ \left(\sigma_{3}-u_{\mathrm{a}}\right): \mathrm{kPa} & \text { elasticity } E_{\text {sat: }} \mathrm{kPa}\end{array}$

Net confining stress

$\left(\sigma_{3}-u_{\mathrm{a}}\right): \mathrm{kPa}$

\author{
elasticity $E_{\text {sat: }} \mathrm{kPa}$
}

Degree of saturation S: \%

\begin{tabular}{ccc}
\hline $76 \cdot 3$ & $83 \cdot 5$ & $92 \cdot 1$ \\
\hline \multicolumn{3}{c}{ Unsaturated modulus of elasticity $E_{\text {unsat: }}: \mathrm{kPa}$} \\
\hline 16667 & 20000 & 10000 \\
20000 & 20000 & 12500 \\
25000 & 25000 & 20000
\end{tabular}

\begin{tabular}{lllll}
\hline 50 & 10000 & 16667 & 20000 & 10000 \\
100 & 10000 & 20000 & 20000 & 12500 \\
200 & 12500 & 25000 & 25000 & 20000
\end{tabular}

Table 4. Experimental values of elasticity moduli obtained from triaxial tests for the compacted specimens of soil $\mathrm{C}$ under saturated and unsaturated conditions (data from Miao et al., 2007)

the four tests that are included in the group. Table 3 shows the net confining stresses for the three groups used in this analysis, which are $25,62 \cdot 5$ and $112 \cdot 5 \mathrm{kPa}$ respectively.

\section{The application of DA for estimating the soil modulus of elasticity}

The first step to apply the DA approach for estimating the modulus of elasticity of unsaturated expansive soils involves calculating the dimensionless parameter $X$ using Equation 6. The data required to calculate $X$ are available for the three soils (i.e. soils A, B and $\mathrm{C})$, which include the initial void ratio $e_{0}$, the net confining stress $\left(\sigma_{3}-u_{\mathrm{a}}\right)$, the matrix suction $\left(u_{\mathrm{a}}-u_{\mathrm{w}}\right)$ and the degree of saturation $S$ (see Appendix A). The second step involves plotting $X$ versus $\left(E_{\text {unsat }}-E_{\text {sat }}\right) / P_{\text {a }}$ obtained from the results of triaxial tests. A good correlation between the two entities $X$ and $\left(E_{\text {unsat }}-E_{\text {sat }}\right) / P_{\text {a }}$ validates the proposed DA approach for estimating the modulus of elasticity of unsaturated expansive soils. Using the regression analysis, the best fit equation can be found for the relationship between $X$ and $\left(E_{\text {unsat }}-E_{\text {sat }}\right) / P_{\text {a }}($ Equation 7) (i.e. the dimensionless model).

Seven controlled-suction triaxial shear tests conducted by Zhan (2003) on unsaturated compacted specimens of soil A, the results of which are available in Zhan (2003), were used in the DA. First, the dimensionless parameter $X$ was calculated using the test data shown in Table A1. Then, plotting the parameter $X$ versus $\left(E_{\text {unsat }}-E_{\text {sat }}\right) / P_{\text {a }}$ for unsaturated specimens tested under each net confining stress leads to satisfactory correlations; the coefficients of determination $R^{2}=0.98$ and 0.97 were obtained for the soil specimens tested under $\left(\sigma_{3}-u_{\mathrm{a}}\right)=50$ and $200 \mathrm{kPa}$ respectively (Figure 7). In the present study, hyperbolic models were chosen to fit the data; however, other trends could be used if they lead to a higher coefficient of determination. The results suggest that the proposed DA can be successfully applied on the triaxial test results of soil A. 
Elasticity moduli of expansive soils from

dimensional analysis

Adem and Vanapalli

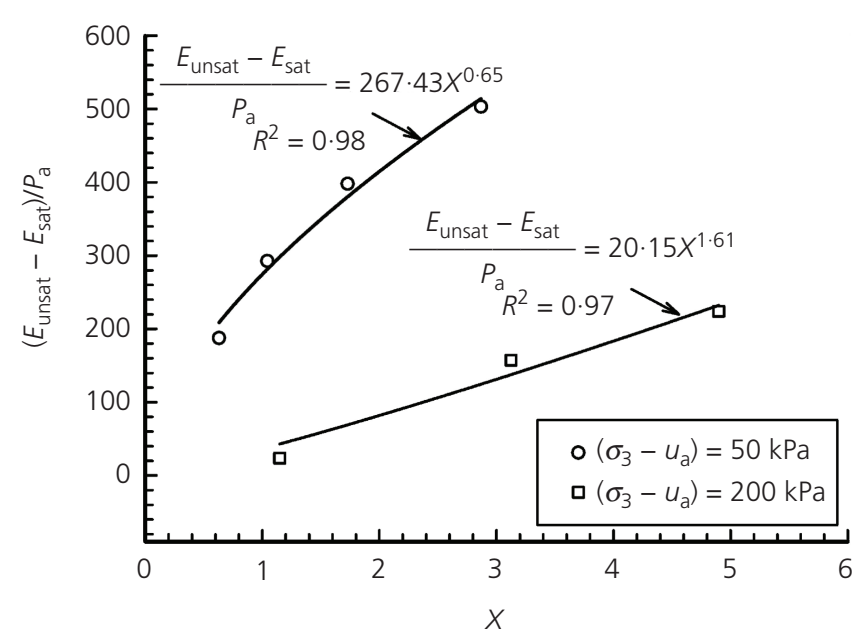

Figure 7. Relationship of $X$ versus $\left(E_{\text {unsat }}-E_{\text {sat }}\right) / P_{\mathrm{a}}$ for the compacted specimens soil A tested under $\left(\sigma_{3}-u_{a}\right)=50$ and $200 \mathrm{kPa}$

Equations 12 and 13 are the hyperbolic models that used to fit the relationships of $X$ versus $\left(E_{\text {unsat }}-E_{\text {sat }}\right) / P$ a for the specimens tested under $\left(\sigma_{3}-u_{\mathrm{a}}\right)=50$ and $200 \mathrm{kPa}$ respectively

12.

$$
\frac{E_{\text {unsat }}-E_{\text {sat }}}{P_{\text {a }}}=267.43(X)^{0.65}
$$

13.

$$
\frac{E_{\text {unsat }}-E_{\text {sat }}}{P_{\text {a }}}=20 \cdot 15(X)^{1.61}
$$

Equations 12 and 13 were used to back-calculate the modulus of elasticity of soil A under unsaturated condition $E_{\text {unsat }}$ for $\left(\sigma_{3}-u_{\mathrm{a}}\right)=50$ and $200 \mathrm{kPa}$ respectively. Figure 8 shows comparisons between the experimental and estimated values of the soil modulus of elasticity $E_{\text {unsat. }}$ A good agreement was observed between the elasticity moduli obtained from the experimental results and the proposed dimensionless model $\left(R^{2}=0.98\right.$ for $\left(\sigma_{3}-u_{\mathrm{a}}\right)=50 \mathrm{kPa}$ and $R^{2}=0.92$ for $\left.\left(\sigma_{3}-u_{\mathrm{a}}\right)=200 \mathrm{kPa}\right)$.

The proposed DA approach was also extended for triaxial tests carried out by Miao et al. (2002) on the compacted specimens of soil $\mathrm{B}$. The initial void ratio, degree of saturation, matrix suction and net confining stress are provided in Table A2 for each test. The dimensionless parameter $X$ was calculated for each test using Equation 6 . The experimental values of elasticity moduli of soil B summarised in Table 3 were used to calculate $\left(E_{\text {unsat }}-E_{\text {sat }}\right) / P_{\text {a }}$. The relationship of $X$ versus $\left(E_{\text {unsat }}-E_{\text {sat }}\right) / P_{\text {a }}$ was plotted for each confining stress (i.e. each group), as shown in Figure 9. Good correlations were found between $X$ and $\left(E_{\text {unsat }}-E_{\text {sat }}\right) / P_{\mathrm{a}}$ for the series of the tests with the exception of the test group of $112 \cdot 5 \mathrm{kPa}$ net confining stress. This set of data appears to be inconsistent with the remainder of the results

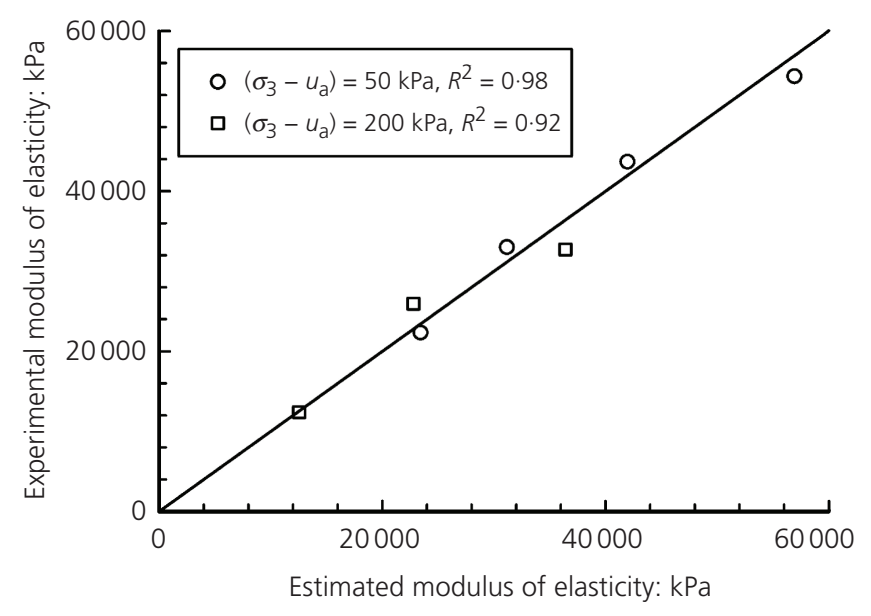

Figure 8. Comparisons between the experimental and estimated values of the unsaturated modulus of elasticity $E_{\text {unsat }}$ for soil $A$

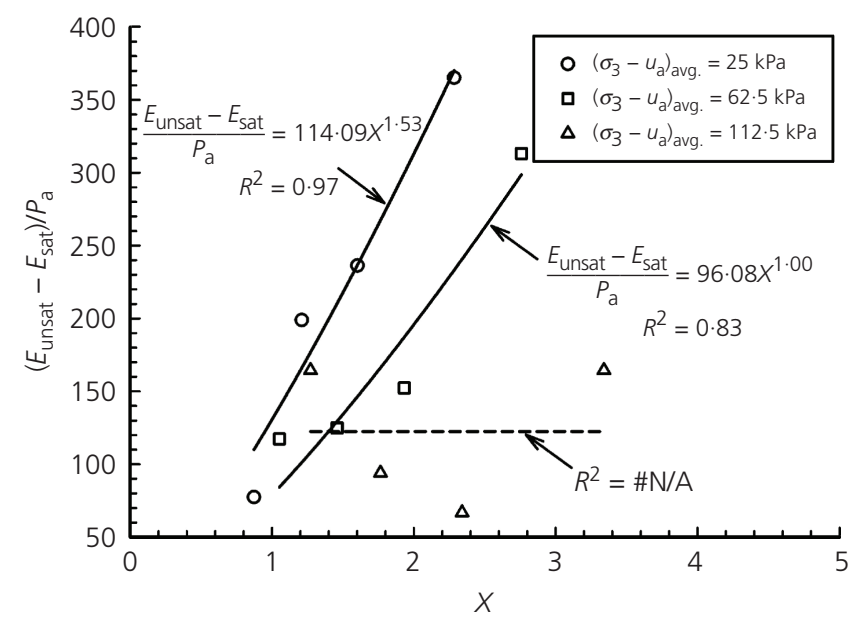

Figure 9. Relationship of $X$ versus $\left(E_{\text {unsat }}-E_{\text {sat }}\right) / P_{\mathrm{a}}$ for the compacted specimens of soil $B$ tested under various net confining stresses

(the test groups of 25 and $62.5 \mathrm{kPa}$ net confining stress). This may be attributed to considering the average of the net confining stresses to represent a group of tests or to a measuring error during some tests that leads to no change in the modulus of elasticity as a response to a change in matrix suction (see Table 3 ).

The relationships between $X$ and $\left(E_{\text {unsat }}-E_{\text {sat }}\right) / P_{\mathrm{a}}$ for the specimens of soil B tested under average values of 25 and $62 \cdot 5 \mathrm{kPa}$ confining stress (Figure 9) can be expressed using Equations 14 and 15 respectively

14. $\frac{E_{\text {unsat }}-E_{\text {sat }}}{P_{\mathrm{a}}}=114.09(X)^{1.53}$ 
Elasticity moduli of expansive soils from

dimensional analysis

Adem and Vanapalli
15. $\frac{E_{\text {unsat }}-E_{\text {sat }}}{P_{\mathrm{a}}}=96.08(X)^{1.00}$

Equations 14 and 15 were used to back-calculate the elasticity moduli of soil B under unsaturated conditions $E_{\text {unsat. }}$. Figure 10 presents the comparison between the experimental and estimated values of the soil modulus of elasticity $E_{\text {unsat }}$. The coefficients of determination were reasonable $\left(R^{2}=0.92\right.$ for $\left(\sigma_{3}-u_{\mathrm{a}}\right)=25$ and $R^{2}=0.8$ for $\left.\left(\sigma_{3}-u_{\mathrm{a}}\right)=62.5 \mathrm{kPa}\right)$. It can be concluded that the unsaturated modulus of elasticity $E_{\text {unsat }}$ at a given confining stress for the compacted specimens of soil B can be reasonably estimated using the DA. However, the applicability of the DA to the test group of $112 \cdot 5 \mathrm{kPa}$ net confining stress requires further investigation.

The other data sets used in this study to validate the proposed dimensionless model for reproducing $E_{\text {unsat }}$ were presented by Miao et al. (2007) (i.e. soil C). The data provided in Table A3 were used to calculate the dimensionless parameter $X$ (Equation 6). Figure 11 shows $\left(E_{\text {unsat }}-E_{\text {sat }}\right) / P_{\text {a }}$, calculated in terms of the experimental values of saturated/unsaturated modulus of elasticity of soil C, versus $X$ for each set of triaxial tests conducted under the same values of net confining stress. Equations 16-18 represent the relationships between $X$ and $\left(E_{\text {unsat }}-E_{\text {sat }}\right) / P_{\text {a }}$ for the data sets under 50, 100 and $200 \mathrm{kPa}$ of net confining stress respectively

16. $\frac{E_{\text {unsat }}-E_{\text {sat }}}{P_{\text {a }}}=10 \cdot 74(X)^{2.62}$

17.

$$
\frac{E_{\text {unsat }}-E_{\text {sat }}}{P_{\mathrm{a}}}=19 \cdot 78(X)^{1.67}
$$

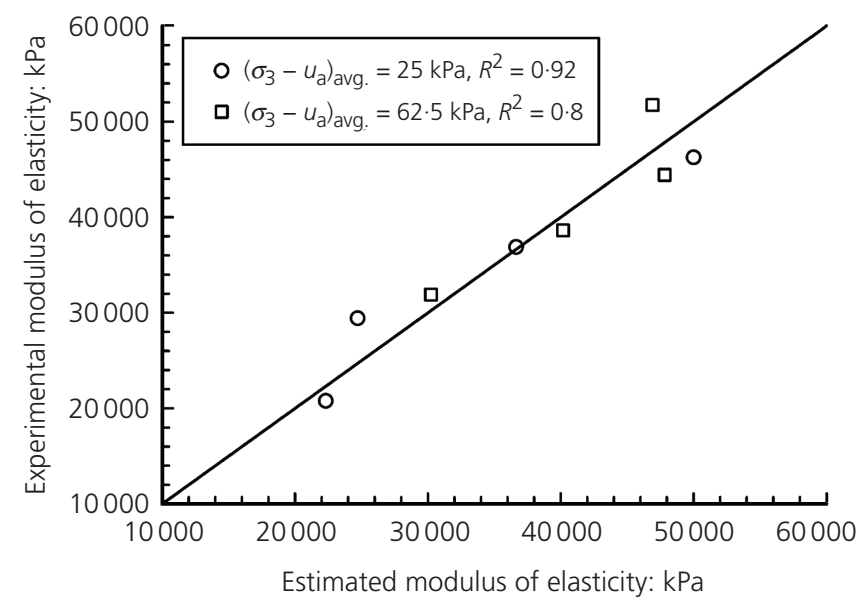

Figure 10. Comparisons between the experimental and estimated values of the unsaturated modulus of elasticity $E_{\text {unsat }}$ for soil $B$

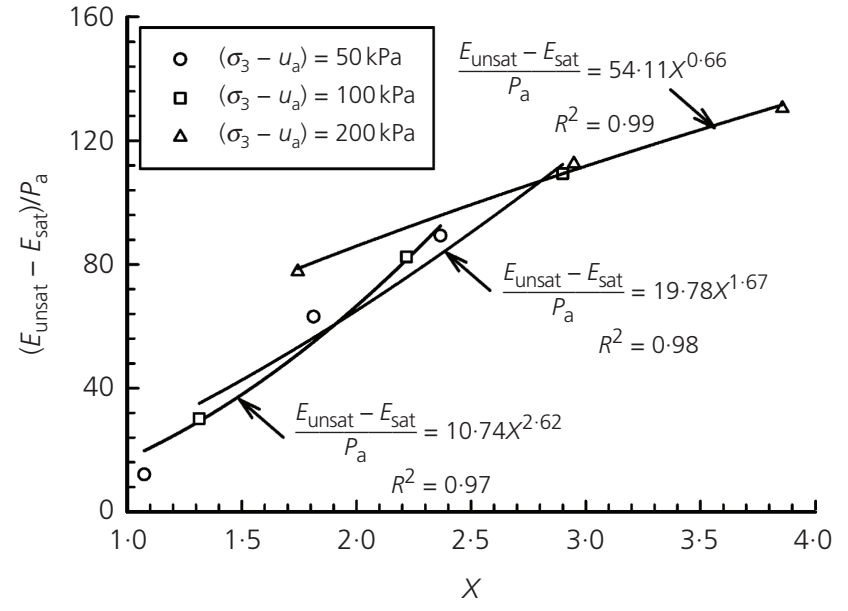

Figure 11. Relationship of $X$ versus $\left(E_{\text {unsat }}-E_{\text {sat }}\right) / P_{a}$ for the compacted specimens of soil $C$ tested under various net confining stresses

18. $\frac{E_{\text {unsat }}-E_{\text {sat }}}{P_{\text {a }}}=54 \cdot 11(X)^{0.66}$

In Figure 11, the coefficients of determination of 0.97, 0.98 and 0.99 were obtained for specimens tested under the net confining stress of 50,100 and $200 \mathrm{kPa}$ respectively. The excellent correlation provides greater degree of confidence for the applicability of the DA approach to the experimental data of soil C.

Figure 12 presents the comparison between the experimental values of $E_{\text {unsat }}$ derived from the triaxial tests and those back-calculated using Equations 16, 17 and 18 for $\left(\sigma_{3}-u_{\mathrm{a}}\right)=50,100$ and $200 \mathrm{kPa}$

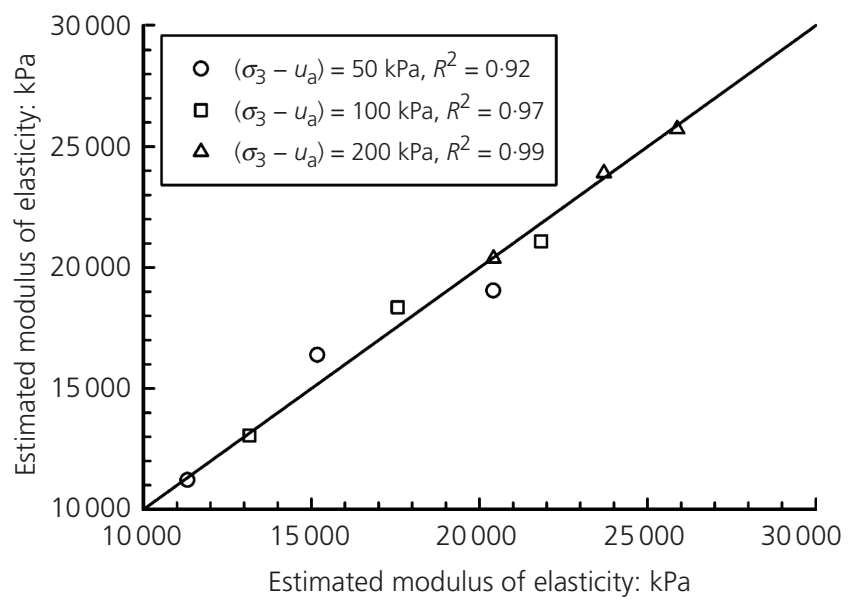

Figure 12. Comparisons between the experimental and estimated values of the unsaturated modulus of elasticity $E_{\text {unsat }}$ for soil $C$ 
respectively. A close agreement was obtained between the values of the elasticity moduli. The correlation was relatively high $\left(R^{2}=0.92,0.97\right.$ and 0.99$)$. Hence, $E_{\text {unsat }}$ at a given net confining stress for the compacted soil $\mathrm{C}$ can be reliably estimated using the proposed dimensionless model.

\section{Verification of the proposed dimensionless model}

A semi-empirical model presented by Adem and Vanapalli (2014) (Equation 19) was used to verify the proposed dimensionless model for estimating the modulus of elasticity of unsaturated expansive soils $E_{\text {unsat. }}$ The semi-empirical model (Equation 19) was proposed by Oh et al. (2009) and Vanapalli and Oh (2010) for the estimation of the unsaturated modulus of elasticity of both coarse and fine-grained soils with plasticity index values $I_{\mathrm{p}}$ lower than $16 \%$ respectively, and then it was extended by Adem and Vanapalli (2014) for unsaturated expansive soils (i.e. $I_{\mathrm{p}}>16 \%$ ).

19.

$$
E_{\text {unsat }}=E_{\text {sat }}\left[1+\alpha \frac{\left(u_{\mathrm{a}}-u_{\mathrm{w}}\right)}{P_{\mathrm{a}} / 101 \cdot 3} S^{\beta}\right]
$$

where $\alpha$ and $\beta$ are the fitting parameters.
The values of unsaturated modulus of elasticity $E_{\text {unsat }}$ for the three expansive soils (soils A, B and C) were reasonably estimated by Adem and Vanapalli (2014) using the semi-empirical model shown in Equation 19. The fitting parameters $\beta=2$ and $\alpha=0 \cdot 05-0 \cdot 15$ were used for the three expansive soils. There was a reasonable agreement between the values of the elasticity moduli obtained from the triaxial shear tests and the semi-empirical model for the three expansive soils studied $\left(R^{2}=0 \cdot 90\right)$ (Adem and Vanapalli, 2014).

Figure 13 presents the comparison between the estimated values of $E_{\text {unsat }}$ obtained from the dimensionless model and the semiempirical model for the three expansive soils (soils A, B and C). It can be seen from Figure 13 that the dimensionless model provides good agreement with the estimations of $E_{\text {unsat }}$ from the semiempirical model. The coefficient of determination was relatively high $\left(R^{2}=0 \cdot 9\right)$. Hence, the proposed dimensionless model can be used for estimating the modulus of elasticity of unsaturated expansive soils $E_{\text {unsat }}$ under any net confining stress (i.e. any loading condition) with varying matrix suctions.

The semi-empirical model proposed by Adem and Vanapalli (2014) for the estimation of the modulus of elasticity of unsaturated expansive soils neglects the influence of the mechanical stress. Such an assumption is conservative and can be extended in practice for pavements and lightly loaded residential structures,

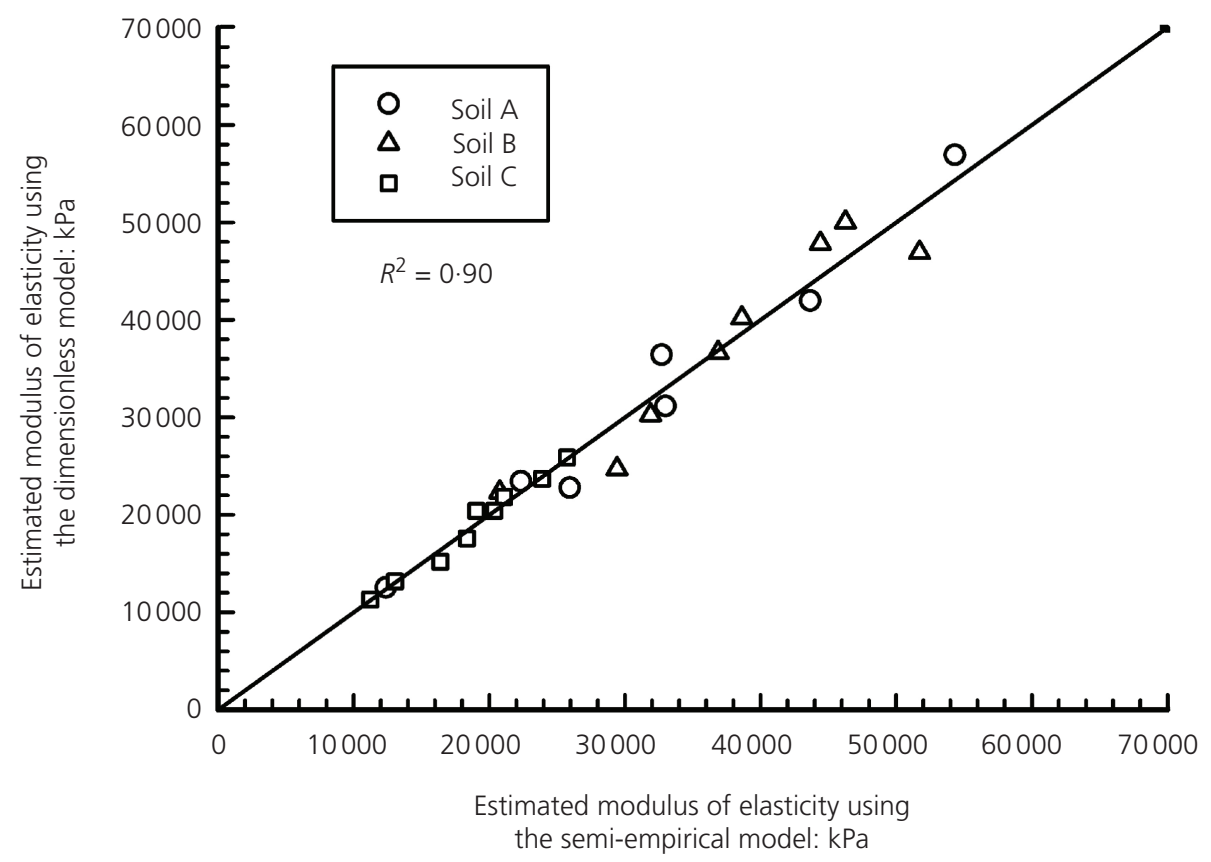

Figure 13. Comparisons between the values of elasticity moduli estimated from the proposed dimensionless model and the semiempirical model for the three investigated expansive soils 


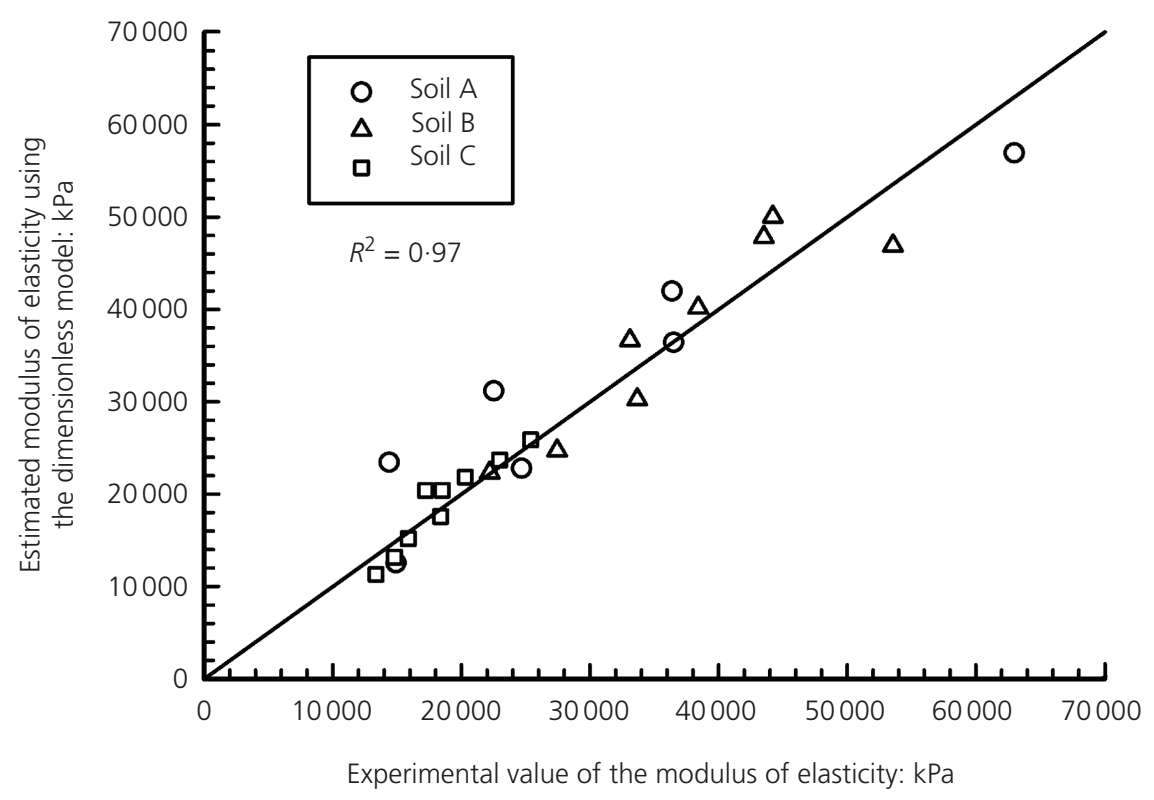

Figure 14. Comparisons between the values of elasticity moduli obtained from the dimensionless model and the triaxial tests for the three investigated expansive soils

where the influence of net normal stress is insignificant and only the soil matrix suction changes have a predominant influence on the behaviour of unsaturated expansive soils. However, the closer agreement between the $E_{\text {unsat }}$ values from the dimensionless model and the triaxial test results with higher coefficient of determination $\left(R^{2}=0.97\right)$ (Figure 14) suggests that the dimensionless model (Equation 7) can be used with greater confidence than the semiempirical model (Equation 19). In other words, the proposed dimensionless model is more rigorous and reliable and can be used for all scenarios of loading conditions (both lightly and heavily loaded structures in expansive soils) for the estimation of the modulus of elasticity of unsaturated expansive soils.

\section{Conclusion}

The DA has been successfully used as a tool to propose a dimensionless model for estimating the modulus of elasticity of unsaturated expansive soils. The model takes into account the effect of the matrix suction and the net confining stress along with the initial void ratio and the degree of saturation towards comprehensive characterisation of the modulus of elasticity of soil under unsaturated condition. Validation of the proposed dimensionless model was conducted using the experimental results of conventional and suction-controlled triaxial tests for three different expansive soils from the literature (soils A, B and C). A good correlation with a high determination coefficient $\left(R^{2}=0.97\right)$ was obtained between the values of the unsaturated modulus of elasticity obtained from the proposed dimensionless model and the results of the triaxial shear tests. More triaxial test results on expansive soils tested under the same values of confining stresses used in this study with different values of matrix suctions are required to calibrate the fitting parameters of the proposed dimensionless model.

The values of unsaturated modulus of elasticity $E_{\text {unsat }}$ for the three expansive soils used in this study were also estimated by Adem and Vanapalli (2014) using the semi-empirical model; these values were used to verify the proposed dimensionless model. The dimensionless model provided good comparisons with the estimations of $E_{\text {unsat }}$ from the semi-empirical model $\left(R^{2}=0 \cdot 9\right)$. The semi-empirical model can be reliably used in practice for pavements and lightly loaded residential structures. However, the proposed dimensionless model can be used for all scenarios of loading conditions (both lightly and heavily loaded structures in expansive soils) with a greater degree of confidence for estimating the modulus of elasticity of unsaturated expansive soils. The strength of this model lies in using soil properties that can be determined from a limited number of conventional laboratory tests to reliably predict the elasticity moduli of expansive soils under variably saturated conditions.

\section{Acknowledgements}

The first author gratefully acknowledges her appreciation to the Libyan Ministry of Higher Education and Scientific Research, which funded her $\mathrm{PhD}$ research program. The second author thanks the support from NSERC for his research programs. The authors also thank Drs L. Miao, L. T. Zhan and C.W.W. Ng for providing their experimental data. 


\section{Appendix A}

\begin{tabular}{lrccr}
\hline$\left(\sigma_{3}-u_{\mathrm{a}}\right): \mathrm{kPa}$ & $\left(u_{\mathrm{a}}-u_{\mathrm{w}}\right): \mathrm{kPa}$ & $e_{0}$ & $S$ & $X$ \\
\hline 50 & 25 & 0.779 & 0.783 & 0.63 \\
50 & 50 & 0.764 & 0.745 & 1.04 \\
50 & 100 & 0.746 & 0.701 & 1.73 \\
50 & 200 & 0.730 & 0.685 & 2.87 \\
200 & 25 & 0.698 & 0.866 & 1.15 \\
200 & 100 & 0.676 & 0.769 & 3.12 \\
200 & 200 & 0.699 & 0.707 & 4.90
\end{tabular}

Table A1. Experimental data for the compacted specimens of soil A under unsaturated conditions (after Zhan, 2003)

\begin{tabular}{lccccc}
\hline$\left(\sigma_{3}-u_{\mathrm{a}}\right): \mathrm{kPa}$ & Average $\left(\sigma_{3}-u_{\mathrm{a}}\right): \mathrm{kPa}$ & $\left(u_{\mathrm{a}}-u_{\mathrm{w}}\right): \mathrm{kPa}$ & $e_{0}$ & $S$ & $X$ \\
\hline 30 & 25 & 50 & 0.8 & 0.71 & 0.87 \\
20 & & 80 & 0.8 & 0.68 & $1 \cdot 21$ \\
30 & & 120 & 0.8 & 0.65 & 1.60 \\
20 & 62.5 & 200 & 0.8 & 0.61 & $2 \cdot 29$ \\
50 & & 50 & 0.8 & 0.71 & 1.05 \\
70 & & 80 & 0.8 & 0.68 & 1.46 \\
80 & 120 & 0.8 & 0.65 & 1.93 \\
50 & & 200 & 0.8 & 0.61 & $2 \cdot 76$ \\
100 & & 50 & 0.8 & 0.71 & 1.27 \\
120 & & 80 & 0.8 & 0.68 & 1.77 \\
130 & & 120 & 0.8 & 0.65 & 2.34 \\
100 & & 200 & 0.8 & 0.61 & 3.34
\end{tabular}

Table A2. Experimental data for the compacted specimens of soil B under unsaturated conditions (after Miao et al., 2002)

\begin{tabular}{lrccc}
\hline$\left(\sigma_{3}-u_{\mathrm{a}}\right): \mathrm{kPa}$ & $\left(u_{\mathrm{a}}-u_{\mathrm{w}}\right): \mathrm{kPa}$ & $e_{0}$ & $s$ & $X$ \\
\hline 50 & 179.37 & 0.824 & 0.76 & 2.37 \\
50 & 121.81 & 0.824 & 0.85 & 1.81 \\
50 & 57.37 & 0.824 & 0.92 & 1.08 \\
100 & 179.37 & 0.824 & 0.76 & 2.90 \\
100 & 121.81 & 0.824 & 0.85 & 2.22 \\
100 & 57.37 & 0.824 & 0.92 & 1.31 \\
200 & 179.37 & 0.824 & 0.76 & 3.86 \\
200 & 121.81 & 0.824 & 0.84 & 2.95 \\
200 & 57.37 & 0.824 & 0.92 & 1.74
\end{tabular}

\section{REFERENCES}

Adem HH and Vanapalli SK (2013) Constitutive modeling approach for estimating the $1-D$ heave with respect to time for expansive soils. International Journal of Geotechnical Engineering 7(2): 199-204.

Adem HH and Vanapalli SK (2014) A simple model for prediction of the modulus of elasticity of unsaturated expansive soils. Accepted for presentation at the UNAST2014 Conference, Unsaturated Soils: Research and Application, Sydney, Australia, 2-4 July.

Alonso EE, Gens A and Josa A (1990) A constitutive model for partly saturated soils. Géotechnique 40(3): 405-430.

Table A3. Experimental data for the compacted specimens of soil $C$ under unsaturated conditions (after Miao et al., 2007)

Barden L, Madedor AO and Sides GR (1969) Volume change characteristics of unsaturated clay. Journal of the Soil Mechanics and Foundation Division ASCE 95: 33-52. 
Buckingham E (1914) On physically similar systems: Illustrating the use of dimensional analysis. Physical Review 4: 345-376.

Butterfield R (1999) Dimensional analysis for geotechnical engineers. Géotechnique 49(3): 357-366.

Buzzi O (2010) On the use of dimensional analysis to predict swelling strain. Engineering Geology 116(1-2): 149-156.

Buzzi O, Giacomini A and Fityus S (2011) Towards a dimensional description of soil swelling behaviour. Géotechnique 61(3): 271-277.

Christophe F, Sell R and Coatanéa E (2008) Conceptual design framework supported by dimensional analysis and system modelling language. Estonian Journal of Engineering 14(4): 303-316.

Costa YD, Cintra JC and Zornberg JG (2003) Influence of matrix suction on the results of plate load tests performed on a lateritic soil deposit. Geotechnical Testing Journal 26(2): 219-227.

Duncan JM and Chang CY (1970) Nonlinear analysis of stress and strain in soils. Journal of the Soil Mechanics and Foundations Division ASCE 96(SM5): 1926-1953.

Fredlund DG and Morgenstern NR (1977) Stress state variables for unsaturated soils. Journal of Geotechnical Engineering Division ASCE 103(GT5): 447-466.

Fredlund DG and Rahardjo H (1993) Soil Mechanics for Unsaturated Soils. Wiley, New York, NY, USA.

Gallipoli D, Gens A, Sharma R and Vaunat J (2003) An elastoplastic model for unsaturated soil incorporating the effects of suction and degree of saturation on mechanical behaviour. Géotechnique 53(1): 123-135.

Inci G, Yesiller N and Kagawa T (2003) Experimental investigation of dynamic response of compacted clayey soils. Geotechnical Testing Journal 26(2): 125-141.

Janbu N (1963) Soil compressibility as determined by oedometer and triaxial test. In Proceedings of the European Conference on Soil Mechanics and Foundation Engineering, Wiesbaden. Deutsche Gesellschaft für Erd- und Grundbau e.V., Essen, Germany, pp. 19-25.

Lu N and Kaya M (2014) A power law for elastic moduli of unsaturated soil. Journal of Geotechnical and Geoenvironmental Engineering 140(1): 46-56.

Lu N and Likos WJ (2006) Suction stress characteristic curve for unsaturated soils. Journal of Geotechnical and Geoenvironmental Engineering 132(2): 131-142.
Matyas EL and Radhakrishna HS (1968) Volume change characteristics of partially saturated soils. Géotechnique 18(4): 432-448.

Miao L, Liu S and Lai Y (2002) Research of soil-water characteristics and shear strength features of Nanyang expansive soil. Engineering Geology 65(4): 261-267.

Miao L, Houston SL, Cui Y and Yuan J (2007) Relationship between soil structure mechanical behavior for an expansive unsaturated clay. Canadian Geotechnical Journal 44(2): 126-137.

Oh WT, Vanapalli SK and Puppala AJ (2009) Semi-empirical model for the prediction of modulus of elasticity for unsaturated soils. Canadian Geotechnical Journal 46(8): 903-914.

Palmer AC (2008) Dimensional Analysis and Intelligent Experimentation. World Scientific, Singapore.

Rahardjo H, Melinda F, Leong EC and Rezaur RB (2011) Stiffness of a compacted residual soil. Engineering Geology 120(1-4): $60-67$.

Vanapalli SK and Adem HH (2013) A simple modeling approach for estimation of soil deformation behaviour of natural expansive soils using the modulus of elasticity as a tool. In Poromechanics V-Proceedings of the Fifth Biot Conference on Poromechanics (Hellmich C, Pichler B and Adam D (eds)). American Society for Civil Engineers, Reston, VA, USA (CD-ROM).

Vanapalli SK and Oh WT (2010) A model for predicting the modulus of elasticity of unsaturated soils using the soil-water characteristic curve. International Journal of Geotechnical Engineering 4(4): 425-433.

Yang SR, Huang WH and Tai YT (2005) Variation of resilient modulus with soil suction for compacted subgrade soils. Transportation Research Record 1913: 99-106.

Yang SR, Lin HD, Kung JHS and Huang WH (2008) Suctioncontrolled laboratory test on resilient modulus of unsaturated compacted subgrade soils. Journal of Geotechnical and Geoenvironmental Engineering 134(9): 1375-1384.

Zhan LT (2003) Field and Laboratory Study of an Unsaturated Expansive Soil Associated with Rain-Induced Slope Instability. $\mathrm{PhD}$ thesis, The Hong Kong University of Science and Technology, Hong Kong.

Zhang D, Liu S and Zhang T (2012) Water content and modulus relationship of a compacted unsaturated soil. Journal of Southeast University (English edn.) 28(2): 209-214.

\section{WHAT DO YOU THINK?}

To discuss this paper, please submit up to 500 words to the editor at journals@ice.org.uk. Your contribution will be forwarded to the author(s) for a reply and, if considered appropriate by the editorial panel, will be published as a discussion in a future issue of the journal. 